\title{
The Potential Effects of Short-Chain Fatty Acids on the Epigenetic Regulation of Innate Immune Memory
}

\author{
Raphael Watt ${ }^{1,2} \mathbb{D}$, Kimberley Parkin ${ }^{1,2}$ and David Martino 1,2,3,*(D) \\ 1 Clinical Epigenetics, Telethon Kids Institute, Nedlands 6009, Australia; \\ raphael.watt@telethonkids.org.au (R.W.); kimberley.parkin@telethonkids.org.au (K.P.) \\ 2 School of Molecular Sciences, University of Western Australia, Crawley 6009, Australia \\ 3 Paediatrics, University of Melbourne, Parkville 3010, Australia \\ * Correspondence: david.martino@telethonkids.org.au; Tel.: +61-8-63191635
}

Received: 27 August 2020; Accepted: 9 October 2020; Published: 12 October 2020

\begin{abstract}
The regulation of innate immunity is substantially more 'plastic' than previously appreciated. Innate immune memory (manifested through trained immunity and tolerance) is a recently described epigenetic phenomenon that is a model example, with broad implications for infectious disease, allergy and autoimmunity. Training the innate immune system to combat infections and temper inappropriate responses in non-communicable diseases will likely be an area of intense research. Innate immunity is influenced by short chain fatty acids, which are the natural products of digestion by the intestinal microbiota that possess inherent histone deacetylase inhibitory properties. It therefore stands to reason that a healthy gut microbiome may well influence mucosal and systemic trained immunity via short chain fatty acids. There is a lack of data on this specific topic, and we discuss potential relationships based on available and preliminary evidence. Understanding the link between intestinal microbiome composition, capacity for short chain fatty acid production and downstream effects on innate immune memory in early life will have important implications for host immunobiology. In this review we explore the intersection between the gut microbiota, short chain fatty acids and epigenetic regulation of innate immunity with a focus on early life.
\end{abstract}

Keywords: innate immunity; short chain fatty acids; gut microbiome

\section{Introduction}

A growing body of evidence now demonstrates that certain subpopulations of myeloid immune cells can develop functionally altered immune responses upon re-exposure to the same or even different stimuli. These adaptive changes, collectively known as 'innate immune memory', can give rise to moderately persistent changes in innate cell function, including proinflammatory cytokine capacity, cell metabolism and effector functions [1]. The two opposing axes of innate immune memory are 'tolerance' and 'trained immunity', where the former describes an attenuation of innate cell proinflammatory cytokine responses whilst the latter describes enhancements to their capability to resolve infection [1,2]. At the nuclear level, innate memory is mediated by pathogen recognition receptor (PRR) signalling events that trigger extensive epigenetic remodelling within myeloid cells, and together with concomitant transcriptional and metabolic changes, can result in modifications to their secondary responses and capacity to resolve infection [3]. Although various layers of the epigenome are involved [4], the accumulation of histone modifications such as acetylation and methylation at immune gene promoters has been identified as a cardinal feature of innate immune memory. Pioneering work in this area has demonstrated that certain vaccines can impart these adaptations upon bone marrow-resident precursor cells and pass them onto their progeny, with systemic effects lasting several months and potentially longer [5]. The clinical implications of these mechanisms are substantial. Innate 
cell tolerance is a beneficial pillar of gut homeostasis and a key mediator of host commensalism, although it has also been linked to severe immunosuppression observed in cases of sepsis [6,7]. Trained immunity on the other hand enhances the proinflammatory potential and effector functions of innate cells, increasing pathogen-agnostic protection, and underpins the nonspecific beneficial effects of certain vaccines [8]. There is much that remains to be determined in order to harness the benefits of innate memory, including the natural ontogeny of these innate responses in the context of human immune development, the role of the identity, dose and duration of the initial inflammatory stimulus as well as how multiple training and tolerising signals are integrated during the course of an immune response.

In addition to these questions, the role of the intestinal microbiome in shaping innate immune memory is also pertinent. Intestinal bacteria derived short-chain fatty acids (SFCAs) are metabolic products of gut commensals of the phyla Bacteroidetes and Firmicutes produced as end products of bacterial metabolism in the large intestine [9]. They are naturally occurring inhibitors of histone deacetylases (HDACs), a class of 'epigenetic reader' enzymes that specifically remove acetyl groups on lysine amino acid residues of histone subunits $[10,11]$. Removal of these modifications allows DNA to wrap more tightly around histones, which is generally associated with transcriptional repression. The SCFAs are therefore modifiers of epigenetic responses by virtue of their HDAC inhibitory activity and can promote the accumulation of transcriptionally permissive acetyl modifications at gene enhancers and promoters. SCFAs constitute a primary source of energy for colonocytes, and they are secreted into the lamina propria where they can exert potent immunomodulatory activity on gut-resident immune cells. They are detectable at much lower levels ( $>1000$-fold) in peripheral blood and likely exhibit reduced activity on circulating cells. These metabolites are therefore a key link between the microbiota and the immune system. It is therefore plausible that the gradient of SCFAs concentrations across the gut and peripheral immune system may influence innate immune memory in dichotomous ways. SCFAs are pharmacologically attractive due to their inherent safety and ability to affect systemic inflammation [12]. Bioavailability of SCFAs is broadly influenced by a number of host and environment-related factors, including composition of the intestinal microbiome, substrate availability and intestinal transit times [9]. We aim to discuss the known immunomodulatory effects of SCFAs and how they might relate to innate immune memory, as well as factors that are likely to influence these processes. At present the specific effects of SCFA on innate memory are unclear but available evidence suggest factors such as dose gradients, metabolic state of responding cells and host-intrinsic factors intersect to determine effects which are likely to be pleiotropic depending upon the situation.

\section{Epigenetic Mechanisms of Innate Immunity}

\subsection{The Role of Histone Modifications and Other Epigenetic Mechanisms in the Regulation of Innate Immunity}

Epigenetics describes the array of post-translational modifications to DNA or DNA-associated proteins that can influence phenotypic variation without alteration of the genetic code. Epigenetic mechanisms such as covalent histone modifications (e.g., acetylation/deacetylation of lysine residues) and chromatin remodelling are critical regulators of host immunity, underpinning the myriad forms of differentiation and phenotypic variation that drive both the innate and adaptive branches of the immune system. In the context of the innate immune system, epigenetic modifications regulate the differentiation of all innate cells from common myeloid progenitors and are responsible for the distinct phenotypic variations present within differentiated cells (e.g., M1 vs. M2 macrophages) [13]. Innate immune cell activity is determined by complex signalling pathways governing the detection of antigens and the innate immune response to infection. Pathogen-associated molecular patterns (PAMP)-mediated activation of surface PRRs and cytokine signalling pathways influence innate immune cell responses through the initiation of downstream transcriptional cascades. These cascades are epigenetically regulated by histone modifications, gene-level chromatin remodelling, microRNAs 
(miRNAs) and DNA methylation, leading to highly dynamic expression of cytokines and other inflammatory mediators, along with an array of anti-infection effector molecules [2,14-16].

Histone acetylation/deacetylation is a core epigenetic mechanism regulating gene expression in the nucleus. It involves the addition/removal of acetyl functional groups on lysine residues in the N-terminus tail of histone proteins. Within the nucleus, DNA is wound around histone proteins to form a complex called chromatin. Chromatin exists in two forms: a highly condensed form called heterochromatin and an uncoiled form called euchromatin. Within heterochromatin, the DNA and histones are packed tightly together, preventing the various transcription factors and RNA polymerases required for transcription from accessing the DNA, leading to repression of gene expression $[17,18]$. Euchromatin describes a loosely packed conformation of DNA/histones within which gene transcription is permissive. Lysine residues in the N-terminus tails of histone proteins are positively charged, attracting the negatively charged DNA strands and promoting a more condensed chromatin conformation $[19,20]$. Acetylation of these residues, facilitated by histone acetyltransferases (HATs), neutralises the positive charge on lysine and allows the chromatin to uncoil, promoting gene expression [21]. Removal of histone acetylation groups is catalysed by HDAC enzymes and condenses the chromatin to repress gene expression. Inhibitors of HDAC enzymes can prevent this process, promoting the accumulation of acetylation of histones at cis-regulatory genomic elements $[15,17,18]$.

It is now known that histone modifications and chromatin remodelling play a critical role in the regulation of innate inflammatory responses. An in vitro study by Lee et al. on human monocytes and macrophages determined that expression of the proinflammatory cytokine TNF- $\alpha$ is separately regulated by both histone acetylation and chromatin remodelling at the gene promoter [22]. Histone $\mathrm{H} 3$ and $\mathrm{H} 4$ acetylation was found to be dependent on the developmental stage of human monocytes and was not regulated by acute immune stimuli. Conversely, chromatin remodelling around the TNF- $\alpha$ promotor was induced by acute inflammatory stimuli, though chromatin remodelling alone was insufficient to activate transcription of TNF- $\alpha$. HDAC inhibitors induced a 22-fold increase in TNF- $\alpha$ secretion following stimulation with the acute inflammatory stimulant paramethoxyamphetamine (PMA), indicating an important role of histone acetylation in this pathway [22]. Park et al. reported that acetylation and phosphorylation of histone $\mathrm{H} 3$ regulates expression of cyclooxygenase-2 (COX-2) in macrophages, a key enzyme in the proliferation of the inflammatory response to LPS [23]. The authors determined that the inhibitory activity of the SCFA butyrate on HDAC3 worked in a synergistic manner with LPS, accentuating COX-2 production by LPS-treated RAW 264.7 macrophages. Butyrate enhanced acetylation of $\mathrm{H} 3$ at the promotor for COX-2. This, in turn, enhanced LPS-mediated phosphorylation of $\mathrm{H} 3$ at the promotor, upregulating expression of COX-2. LPS alone had no effect on H3 phosphorylation [23]. This proinflammatory activity of butyrate appears to contrast with the anti-inflammatory activity reported in studies investigating the effects of butyrate on proinflammatory cytokine production $[24,25]$. This apparent variation in inflammatory activity may arise from secondary activation and targeting of nuclear repressor complexes to promotor sites of inflammatory genes by acetylated histone $\mathrm{H} 3$, as suggested by Chang et al. [26].

DNA methylation has been relatively understudied as a regulatory mechanism of the innate immune response, due to the belief that methylation marks are highly stable in the context of inflammation. Recent studies have challenged this idea, reporting significant changes in DNA methylation in innate immune cells following infection. Infection of human dendritic cells (DCs) and macrophages with live Mycobacterium tuberculosis was found to lead to the active loss of DNA methylation at thousands of enhancers throughout the genome $[27,28]$. These changes were predictive of altered expression at nearby genes, with multiple studies reporting similar findings [29-32], however there is currently insufficient evidence to suggest a causal relationship between changes in DNA methylation and changes in gene expression in response to infection. Pacis et al. reported that the vast majority of changes in gene expression in response to infection occurred prior to any changes in DNA methylation [28]. These findings suggest that changes in the DNA methylation profiles of 
immune cells following infection are likely the result of downstream surface receptor signalling and transcriptional activation.

miRNAs are small noncoding RNAs that play important roles in RNA silencing and posttranslational regulation of gene expression through complementary base-pair binding with target mRNAs. miRNAs may contribute to the development of innate immune memory through a combination of their long half-life [33] and the limited proliferative ability of myeloid cells. These factors allow miRNAs to persist within myeloid cells following the removal of a primary stimulus, where they may continue to influence the immune response to later stimuli [34]. One such miRNA that may act in this way is miR-155, which is upregulated in response to inflammatory signals and is associated with hyperactivation of myeloid cells. This pro-inflammatory activity is likely due to miR-155-mediated repression of Src homology-2 domain-containing inositol 5-phosphatase 1 (SHIP1), leading to increased activation of the kinase Akt during the cellular response to microbial antigens [35]. It is possible that sustained intracellular levels of miR-155 following exposure to a primary stimulus could cause myeloid cells to adopt a hypersensitive phenotype, promoting an enhanced inflammatory response upon exposure to a secondary stimulus.

\subsection{Epigenetic Mechanisms of Innate Immune Memory}

The cellular basis of innate immune memory is the functional reprogramming of innate immune cells and associated changes in chromatin conformation through histone modifications, changes in the accessibility of DNA to regulatory elements that drive transcriptional and metabolic changes [36]. Stimulation of myeloid cells with antigen, lipids and certain vaccine products can leave an epigenetic 'imprint' - a pattern of epigenetic changes at enhancers and promoters at host-defence genes that can lead to heightened responsiveness (trained immunity) or suppressed responsiveness (tolerance) on re-encounter.

Trained immunity arises when some microbial and vaccine antigens cause monocytes/macrophages to make an adaptative response to secondary challenge by increasing their proinflammatory cytokine response to a broad range of microbial stimuli, also known as heterologous protection. This pathogenagnostic immunity underpins the nonspecific protective effects of the BCG vaccine, among others [37-39]. Trained immunity is dependent on epigenetic remodelling and changes in intracellular metabolic pathways. Activation of these pathways induces innate cells to adopt an augmented proinflammatory phenotype characterised by employing increased acute inflammatory cytokine responses, which can persist on a long term basis $[3,14,40,41]$. Recent in vitro and in vivo studies have revealed that the state of trained immunity is induced by PAMPs through PRR signalling [41,42]. An initial study in mice found that infection with an attenuated strain of fungal $C$. albicans protects against infection with bacterial S. aureus. In vitro studies revealed that the fungal cell wall component $\beta$-glucan acts as a PAMP to induce functional reprogramming and extensive epigenetic remodelling in innate cells through a dectin-1/Raf1-dependent pathway $[43,44]$. It was then discovered that inoculation of healthy human volunteers with the BCG vaccine caused lasting and nonspecific upregulation of isolated monocyte proinflammatory cytokine responses ex vivo, with these effects persisting for at least three months following vaccination. Further research determined that these altered cytokine responses are dependent on nucleotide-binding oligomerisation domain-containing protein 2 (NOD2)-signalling and epigenetic histone modifications promoting the transcription of proinflammatory genes, and likely explain the observed beneficial effects of BCG vaccination on mortality [45-47]. Most recently, atherogenic lipid oxidised low-density lipoprotein (ox-LDL) has been found to induce a proatherogenic phenotype in monocytes, increasing proatherogenic cytokine secretion in vitro. This new, though less studied, form of trained immunity is mediated by TLR4/TLR2 signalling and activation of phosphatidylinositol 3-kinase (PI3K) and mitogen-activated protein kinase (MAPK), leading to downstream changes in histone methylation and gene transcription $[48,49]$. The broad protective properties of $\beta$-glucan and the BCG vaccine have led to a recent surge in interest in research investigating trained immunity in a range of different organisms and diseases [16,50]. 
The other molecular aspect of innate immune memory is tolerance, a refractory state of innate cells characterised by a greatly reduced proinflammatory cytokine response to infection and plays a cardinal role in both health and disease [16]. Recent studies have demonstrated that LPS-induced tolerance is linked to specific epigenomic changes in innate monocytes/macrophages, characterised by differences in primed active and distal genomic elements. Transcriptomic analysis of tolerant monocytes from both septic patients and mouse models of sepsis suggests that the tolerant phenotype is dependent on chromatin remodelling and regulatory nuclear proteins modulating the expression of tolerised genes [51,52]. These findings were confirmed in a study by Novakovic et al. utilising in vitro models of LPS-induced tolerance in human monocytes. This study found that histone acetylation/methylation marks of transcriptional activity were highly dynamic, varying greatly between LPS-treated macrophages (LPS-Mfs) and untreated macrophages (naïve-Mfs) [41]. These histone modifications influence the conformation of chromatin in the nucleus, regulating transcription in an epigenetic manner. Acetylation of the 27th lysine residue on histone 3 (H3K27ac) at promoters and enhancers, a mark associated with transcriptional activation [53], was observed to be the most dynamic, with the largest variations being associated with monocyte differentiation into macrophages. Untreated cells established macrophage differentiation-specific active regions within $24 \mathrm{~h}$, while LPS-treated cells exhibited delayed differentiation, establishing a number of proinflammatory active regions before "catching up" and establishing similar differentiation marks once the stimulus was removed at $24 \mathrm{~h}$. Chromatin segmentation analysis with EpicSeq confirmed that LPS-Mfs maintained a chromatin state similar to undifferentiated monocytes, with genes essential for phagocytosis and cytokine release in mature macrophages rendered inactive. This suggests that tolerant cells may be a form of adapted monocytes and not simply late differentiated macrophages [41]. These findings demonstrate that the development of innate immune tolerance is dependent on specific epigenetic mechanisms, with posttranslational histone modifications governing the expression of genes that are specific for both macrophage differentiation and inflammation.

\subsection{Short Chain Fatty Acids: A Novel Class of Histone Deacetylase Inhibitors}

SCFAs are a class of metabolite that acts as a link between the microbiota and immune development and function. SCFA are carboxylic acids with aliphatic tails of 1-6 carbons and are produced through fermentation of dietary fibre, carbohydrates and peptide and glycoprotein precursors [54]. The three major gut derived SCFAs, acetate, butyrate and propionate, are potent inhibitors of HDACS in innate cells, primarily through inhibition of histone deacetylase 3 (HDAC3) [10,11,55]. Concentrations of SCFAs vary widely across the gut and peripheral circulation. Estimates for concentrations of acetate, propionate and butyrate range from $70-140 \mathrm{mM}$ in the proximal colon, $20-70 \mathrm{mM}$ in the distal colon [12] to as low as $0.16-25.05 \mu \mathrm{M}$ in circulation. The ratio of acetate/propionate/butyrate in the gut is roughly $60 / 20 / 20$, though the relative concentrations of propionate and butyrate are far lower in the circulation, with butyrate circulating at $\sim 0.16 \mu \mathrm{M}$ and propionate circulating at $\sim 0.62 \mu \mathrm{M}$ compared to $\sim 25 \mu \mathrm{M}$ for acetate [56]. SCFA exert their effects by acting as ligands for G-couple protein receptors (GPCRs), passive diffusion through the cell membrane, stimulation of histone acetyltransferases, inhibition of HDACs and stabilisation of the hypoxia-inducible factor (HIF) [12,57]. Through these pathways, they influence a broad range of cellular processes including proliferation, differentiation, chemotaxis, gene expression, epigenetic remodelling, cytokine production and apoptosis [12]. The receptors that internalize SCFA exhibit varied expression across cells and tissues, which is partially associated with the range of effects on cell biology.

Several studies have begun to investigate the therapeutic potential of SCFA in clinical trials as a naturally occurring alternative to conventional HDAC inhibitors. Conventional HDAC inhibitors are clinically approved for the treatment of cancer and have been found to induce cell cycle arrest, differentiation, cell death and reduced angiogenesis in tumours [58,59]. Though well tolerated compared to classical chemotherapeutic agents, their toxicity has limited their applications outside of oncology. HDAC inhibitors have poor specificity for diseased cells, leading to off-target widespread aberrant 
gene expression [60-62]. SCFAs on the other hand are produced naturally in the gut and are non-toxic, being well tolerated even in very high (mM) concentrations [56]. Most significantly, SCFAs selectively target innate immune cells by activating free fatty acid receptors 2 and 3 (FFAR2/FFA2/GPR43) and (FFAR3/FFA3/GPR41), expressed predominantly on the surface of peripheral blood mononuclear cells (PBMCs), monocytes, and neutrophils. FFAR2/3-mediated signalling ensures a high degree of specificity in the anti-inflammatory effects of SCFAs $[63,64]$. These properties are unique among HDAC inhibitors and position SCFAs as an attractive target for the treatment of chronic disease. Clinical approaches to short chain fatty acid therapy fall into the category of either 1-direct delivery or 2-dietary intervention strategies that modulate the host microbiota in order to boost bioavailability of SCFA, either as prenatal prevention strategies or as a therapy. A brief search on PubMed reveals over 100 randomised controlled or clinical trials published on short chain fatty acids, with treatment applications in inflammatory bowel and gastrointestinal disorders [65-67], diabetes and obesity [68-70], cancer [71], prematurity [72], neurological disease [73] and psychosocial stress [74]. The translation of SCFA therapy into clinic as a proven prevention strategy or treatment is still on the horizon, however it is already common parlance to espouse the generalised benefits of a high fibre diet to boost gut health and reduce disease risk.

The effects of SCFAs on DNA methylation and miRNAs in innate immunity are poorly understood. While a small number of studies have investigated the effects of SCFAs on DNA methylation, these studies have focussed on cell populations outside of the immune system. This paucity of immunological data extends to studies exploring the effects of SCFAs on miRNAs, with the few existing studies focussing primarily on cancer. As current data are insufficient, further research is necessary before the immunological effects of SCFAs on these epigenetic processes can be determined.

\subsection{SCFA Effects on Innate Immune Function}

SCFA exhibit varied and somewhat potent immunomodulatory effects on innate (and adaptive) immune cells resident in the mucosal associated lymphoid tissues, and at distal sites. Epithelial cells are key barrier components of the innate immune system and display innate like characteristics. SCFA play an essential role in regulating intestinal epithelial physiology, through maintaining barrier functions, cell division and modulating responses after infection/inflammation. Colonocytes utilise SCFA as a primary energy source, and butyrate in particular plays a role in colonocyte proliferation and apoptosis [75]. Butyrate also increases intestinal epithelial cell production of antimicrobial peptides indicating a role in host defence [76]. SCFAs increase the production of cytokines (TNF-a, IL-6) and chemokines (CXCL10, CXCL1) in vitro [77]. Activation of GPCRs induces membrane hyper-polarization, an increase in potassium ion influx and activation of the inflammasome NLPR3, increasing production of IL-18 a key cytokine that regulates repair and maintenance of epithelial barrier integrity [78]. GPCR-independent effects attributable to HDAC inhibitory activity have been noted to dampen production of neutrophil chemotactic chemokines (CCL20, CXCL8) and have also been described in in vitro models of gut epithelial cells [79].

In addition to barrier cells, many studies have shown that monocytes and macrophage function are also influenced by microbiota metabolites. SCFA have been reported to dampen proliferative responses in macrophages [80], as well as inflammatory cytokine production [26,81,82], whilst also increasing production of prostaglandins [83] and host defence peptides [84]. Murine macrophage cells exposed to SCFA display decreased production of LPS-induced TNF-a, IL-1B and IL-6, with enhanced production of IL-10 [81,82]. Bone-marrow derived macrophages exposed to butyrate in vitro exhibited reduced nitric oxide production and anti-inflammatory cytokine effects but this was not observed with propionate or acetate [26]. In macrophages, butyrate exhibits HDAC inhibitory activity and an increase in histone H3K9ac at the promoters of $I l 2$, Nos2 and $I l 12 b$ [26]. Park et al. reported the inhibitory activity of the SCFA butyrate on HDAC3 augmented COX-2 production in LPS-treated RAW 264.7 macrophage cell lines, which occurred via accumulated acetylation of $\mathrm{H} 3$ at the promotor for COX-2 [23]. This proinflammatory activity of butyrate appears to contrast with the anti-inflammatory activity 
reported in studies investigating the effects of butyrate on proinflammatory cytokine production. Other studies have shown increased production of prostaglandin E2 in human monocytes [83] and increased production of host defence peptides [84]. There are some discrepancies in the pro- versus anti-inflammatory effects of SCFA on monocytes and macrophages which likely to be explained, at least in part, to differences in experimental parameters such as the use of primary cultures versus immortalized cell lines, as well as the different type and dose of SCFA examined.

Dendritic cells (DCs) are central immune surveillance components of the innate immune system, and several studies have now investigated the effects of SCFA on DCs. In general, these effects inhibit DC expression of activation markers CD80 and CD83, CD1a and MHC class II molecules [81], reducing their capacity to stimulate T-cell responses [85]. DC development appears to be attenuated in the presence of butyrate [86], which has been proposed to occur through HDAC inhibition activity and suppression of transcription factors PU.1 and RELB, which play a role in DC development [86]. Innate lymphoid cells are tissue resident cells that are abundant at the mucosal surfaces and rapidly expand in response to infection and tissue damage. Administration of a diet high in soluble fibres such as pectin and inulin, which increase microbiota metabolism of SCFA in the blood, supports expansion of ILC subpopulations in the intestine of mice [87]. Signalling through GPCR receptors can induce the expression of free fatty acid receptors Ffar2 and Ffar3 on ILCs and activates PIK3-mTOR glycolytic switch to drive proliferation [87]. In the airways, dietary fibre derived butyrate suppresses ILC2 production of allergic inflammatory type 2 cytokines via downregulation of the GATA3 lineage-determining transcription factor. This biological effect is associated with reduced lung inflammation in murine models of airways hyperreactivity [88]. Other models of allergic airways disease have reported reduced eosinophilic-mediated type 2 inflammation in mice injected with butyrate [89]. In human eosinophils, SCFA attenuated migration, adhesion and survival via GPCR independent mechanisms accompanied by increased histone acetylation [89].

\section{The Role of the Microbiota in the Regulation of Short Chain Fatty Acids}

\subsection{Ontogeny of Gut SCFA Producers}

Given SCFA are end products of bacterial metabolism in the large intestine, bioavailability of these metabolites is influenced by colonisation patterns in the gut. The SCFA are formed principally by anaerobic microbes through fermentation of indigestible starches and plant cell-wall polysaccharide substrates [9]. The composition of the microbiota is therefore one important host-related factor that regulates SCFA production. The main phyla that produce SCFA include the Bacteroidetes and Firmicutes [90], which begin to colonise and dominate the gastrointestinal tract (GIT) during infancy and early childhood, around the time that solid foods are introduced into an infant's diet. Microbiome research has shown that the spatio-temporal colonisation of the gut microbiome in early life is highly influenced by environmental and lifestyle related factors, which likely also influence the regulation of SCFA [91].

The initial seeding of the intestinal microbiome may begin as early as in utero [92], and neonatal factors including the mode of delivery can influence diversity and colonisation pattern for the first six months of life [93]. Maternal diet may influence the abundance of some species in the neonate [94], and neonatal antibiotic therapy is a major disruptor of initial colonisation [95]. After birth, the infant gut microbiome is primarily colonised by bacteria belonging to the Enterobacteriaceae, Bifidobacterium, and Staphylococcus genus, which are specialised at processing milk oligosaccharides [96]. As mentioned above, the SCFA producers begin to colonise in early infancy as the diet becomes more diverse and complex. Within the Firmicutes phylum around this time, the main butyrate producing bacteria are Faecalibacterium prausnitzii and Clostridium leptum from the Ruminococcaceae family, and Eubacterium rectale and Roseburia spp. from the Lachnospiraceae family [97]. In the infant gut, a distinct endospore community constitute major butyrate-producing taxa. This community initially exhibits low diversity and abundance (compared with adults) and increases over time with 
the availability of dietary and endogenous glycans, correlating with increased butyrate levels in infant stool samples $[98,99]$. In postnatal life, factors known to influence the early development of the infant gut microbiome include medication use, premature birth, formula feeding, cohabitation with pets and siblings [100], and it is likely that SCFA levels may vary in a population according to these factors.

\subsection{Impact of the Microbiome on Innate and Adaptive Immunity}

Within the human body the most diverse and species-rich of the microbiomes reside in the GIT Microbial communities in the gut can influence host responses locally at tissue surfaces, or distally through secreted soluble factors that circulate and influence systemic immunity. Local interactions in occur in the large and small intestinal tissue which is abundant in both innate cells and Band T-lymphocytes. Bacterial adhesion to the gut epithelium can influence intestinal epithelial cell responses [101], and constant signalling to mucosal dendritic cells via PRR promotes antigen-specific tolerance [102]. Secretion of SCFA and other metabolites, vitamins, sphingolipids, bacterial DNA, peptides and polysaccharides and transport to the lamina propria can influence mucosal-resident immune cell populations [103]. Perhaps the most robust evidence for the crucial role of the intestinal microbiota in influencing local immune responses comes from studies of germ-free mice. Germ-free mice display profound morphological defects in the structures of the gut-associated lymphoid tissue and mesenteric lymph nodes, as well as reduced numbers and function of T- and B-lymphocytes in the lamina propria [104]. This illustrates the significant effect GI colonisation has in driving maturation of the mucosal-associated lymphoid tissue.

The intestinal microbiota can also influence systemic immunity through translocation of bacterial products such as lipopolysaccharide (LPS) or metabolites such as SCFA from mucosal niches to systemic circulation. Thus microbiota-derived metabolites can be detected at distal sites by the immune system, and influence those responses [105]. Tissues such as the bone-marrow, lungs, liver and spleen can respond to bacterial-derived antigens and metabolites [104]. Disruption of the microbiota can therefore have wide-ranging effects on immunity. Germ-free and antibiotic treated mice exhibit reduced capacity to clear viral infection and attenuated antibody responses [105]. Both IgM and $\mathrm{IgG}$ antibody responses to seasonal flu vaccine are substantially reduced, and can be restored upon reconstitution [106]. These studies suggest the microbiota is an important modulator of antibody responses to vaccination. Perhaps counter-intuitively, antibiotic treated mice exhibit enhanced T-cell mediated immune memory responses to vaccine antigen [107]. Supportive evidence in humans is suggestive but not robust with correlative studies suggesting associations between gut microbiota and vaccine immunity. Differences have been noted between vaccine responders and non-responders after oral rotavirus vaccination $[108,109]$. The abundance of Bifidobacterium in early infancy has been linked to immune responses to oral polio vaccine, BCG, tetanus toxoid and hepatitis B [110]. Although only a few intervention studies have been attempted to date, one randomised placebo-controlled trial investigated the hypothesis that gut intestinal pathogens might reduce the effectiveness of oral polio vaccine given to infants in the developing world [111]. 6-11-month-old infants were randomised to receive either a 3-day course of azithromycin or placebo prior to administration of the oral polio vaccine. There was no difference in the development of serum neutralising antibodies to polio. This study did report that viral pathogens (which were not cleared by antibiotics) were associated with reduced sero-conversion suggesting innate anti-viral mechanisms may interfere with vaccine efficacy.

In a second intervention trial using antibiotics, Hagan et al. [112] administered broad spectrum antibiotics to health adults for 5-days before immunizing with the seasonal flu vaccine 1-day prior to cessation of the antibiotic course. Despite significant reductions in the gut microbiota community, no differences in neutralising antibody production after vaccination. In a second trial of subjects that had no prior exposure to the seasonal flu vaccine, nor a history of infection with flu for the previous 3 years, antibiotics administration was associated with a reduction in specific IgA and IgG1 titres and an ability to neutralise the H1N1 strain. Collectively this study suggests pre-existing T-memory 
dependent immunity may be less dependent on the natural adjuvant effects of the gut microbiota, whereas primary responses to novel antigen appear to be sensitive to gut dysbiosis.

\section{Do SCFAs Affect Trained Immunity?}

The present state of the field is such that the relationships between SCFA and innate immune memory are unclear due to a lack of specific research on this. As described above, SCFAs exhibit immunomodulatory potential on many cells of the innate immune system. It is therefore feasible that the processes of innate immune memory (trained immunity and tolerance) could be influenced or modified by these metabolites, assuming they are present at the time of initial antigen priming. At present there are a lack of studies that have specifically addressed this. Based on available literature, we speculate that that pleotropic effects will occur depending on the intersection between dose encountered, the metabolic state of immune cells and host-intrinsic factors such as the composition of the microbiome.

Dose gradients appear to be important potential influencers on outcomes with respect to innate memory. In a study of tumorigenic colonocytes, butyrate was found to stimulate histone acetylation in a dose-dependent manner by distinct mechanisms. At high concentrations such as would be encountered by colonocytes and gut-resident immune cells, HDAC inhibition predominated, which can lead to hyperacetylation of histones and transcription factors, and in cancerous cells, inhibition of cell proliferation and promotion of apoptosis [75]. It is plausible that these effects might promote trained immunity in innate cells through increasing histone acetylation at promoters and enhancers. At low concentrations, butyrate metabolised in the mitochondria is converted to acetyl-CoA, an essential factor for the acetylation of histones and other proteins. Although both mechanisms increase histone acetylation, the latter mechanism has been shown to increase proliferation in colonocytes via a distinct gene expression program [75]. As mentioned previously, the abundance of Bacteroidetes and Firmicutes phyla in the gut (as well as other host-related factors) will likely affect SCFA concentration gradients. The metabolic state of immune cells exposed to SCFA metabolites might also determine outcomes with respect to innate memory capacity. Highly proliferative or activated cell types tend to rely on glucose as an energy source (the Warburg effect). This metabolic shift changes the production of acetyl-CoA and likely invokes the HDAC inhibitory effects of SCFA, whereas cells utilising oxidative metabolism might respond differently [75]. The combination of these effects will likely determine how these metabolites influence the capacity for innate memory.

In the circulation, SCFA levels are exceedingly lower and effects on systemic immunity are unclear. The most well-demonstrated ex vivo models of trained immunity and tolerance in the lab are performed on monocytes, or NK cells. There is a paucity of data around whether these ex-vivo models are affected by the addition of SCFA to culture media, and how this might inhibit/augment processes, despite evidence of immunomodulatory effects of SCFA on monocytes and macrophages. There is one clinical study that has looked at the system anti-inflammatory effects of sodium butyrate supplementation on the induction of trained immunity [113]. Oral administration of sodium butyrate for 4 weeks in a cohort of ten obese adult males exhibiting metabolic syndrome, and nine lean male controls, dampened inflammatory cytokine production (IlL-6, TNF-a, IL-10) in trained monocytes. No difference in cytokine production was observed after direct stimulation of peripheral blood mononuclear cells (PBMCs) with various heat-killed microbial pathogens, suggesting potential selective inhibition on the induction of trained immunity, the latter mechanism being dependent on histone acetylation. In this study, the intervention did not appreciably alter levels of plasma or faecal butyrate, acetate or propionate in subjects. Of note, the effects on trained immunity were only observed in the obese group, suggesting a possible role for diet or the microbiome in this group. While this study was not definitive, it suggests that butyrate supplementation may increase local concentrations in the gut, where it can affect the metabolism of circulating monocytes, but further evidence of this is needed. 


\section{Conclusions}

Trained immunity and tolerance are two exciting modes of 'innate immune memory', a process that challenges the dogma that innate responses are static. The epigenetic processes that bring about innate memory mediate plasticity in cellular phenotypes and depend upon mechanisms such as histone acetylation to establish gene expression programs. There is great interest in harnessing the power of trained immunity and tolerance for next generation vaccine design, to boost host immunity in a pathogen agnostic fashion, and as a potential strategy against sepsis. It is likely that innate memory capacity varies considerably within and across populations, and the gut microbiota is likely to be one important influencer of innate immune cell plasticity. Strategies that harness trained immunity or tolerance will need to consider this an important host-related factor when attempting to optimise innate responses. At present it is unclear how SCFA affect innate immune memory, but available evidence suggests effects are likely to be pleotropic depending upon concentration gradients and the metabolic state of cells encountering these metabolites. Further research in this area is needed.

Funding: This research received no external funding.

Conflicts of Interest: The authors declare no conflict of interest.

\section{References}

1. Netea, M.G.; Joosten, L.A.B.; Latz, E.; Mills, K.H.G.; Natoli, G.; Stunnenberg, H.G.; O’Neill, L.A.J.; Xavier, R.J. Trained immunity: A program of innate immune memory in health and disease. Science 2016, $352,427$. [CrossRef]

2. Seeley, J.J.; Ghosh, S. Molecular mechanisms of innate memory and tolerance to LPS. J. Leukoc. Biol. 2017, 101, 107-119. [CrossRef] [PubMed]

3. Arts, R.J.W.; Moorlag, S.J.C.F.M.; Novakovic, B.; Li, Y.; Wang, S.Y.; Oosting, M.; Kumar, V.; Xavier, R.J.; Wijmenga, C.; Joosten, L.A.B.; et al. BCG Vaccination protects against experimental viral infection in humans through the induction of cytokines associated with trained immunity. Cell Host Microbe 2018, 23, 89-100. [CrossRef] [PubMed]

4. Fanucchi, S.; Mhlanga, M.M. Lnc-ing Trained Immunity to Chromatin Architecture. Front. Cell Dev. Biol. 2019, 7, 2. [CrossRef] [PubMed]

5. Kaufmann, E.; Sanz, J.; Dunn, J.L.; Khan, N.; Mendonça, L.E.; Pacis, A.; Tzelepis, F.; Pernet, E.; Dumaine, A.; Grenier, J.C.; et al. BCG Educates hematopoietic stem cells to generate protective innate immunity against tuberculosis. Cell 2018, 172, 176-190. [CrossRef]

6. Vachharajani, V.; McCall, C.E. Epigenetic and metabolic programming of innate immunity in sepsis. Innate Immun. 2019, 25, 267-279. [CrossRef]

7. Venet, F.; Monneret, G. Advances in the understanding and treatment of sepsis-induced immunosuppression. Nat. Rev. Nephrol. 2018, 14, 121-137. [CrossRef]

8. Covián, C.; Fernández-Fierro, A.; Retamal-Díaz, A.; Díaz, F.E.; Vasquez, A.E.; Lay, M.K.; Riedel, C.A.; González, P.A.; Bueno, S.M.; Kalergis, A.M. BCG-Induced Cross-Protection and Development of Trained Immunity: Implication for Vaccine Design. Front. Immunol. 2019, 10, 1-14. [CrossRef]

9. Macfarlane, S.; Macfarlane, G.T. Regulation of short-chain fatty acid production. Proc. Nutr. Soc. 2003, 62, 67-72. [CrossRef]

10. Shakespear, M.R.; Halili, M.A.; Irvine, K.M.; Fairlie, D.P.; Sweet, M.J. Histone deacetylases as regulators of inflammation and immunity. Trends Immunol. 2011, 32, 335-343. [CrossRef]

11. Li, M.; van Esch, B.C.A.M.; Wagenaar, G.T.M.; Garssen, J.; Folkerts, G.; Henricks, P.A.J. Pro- and anti-inflammatory effects of short chain fatty acids on immune and endothelial cells. Eur. J. Pharmacol. 2018, 831, 52-59. [CrossRef] [PubMed]

12. Corrêa-Oliveira, R.; Fachi, J.L.; Vieira, A.; Sato, F.T.; Vinolo, M.A.R. Regulation of immune cell function by short-chain fatty acids. Clin. Transl. Immunol. 2016, 5, 1-8. [CrossRef] [PubMed]

13. Álvarez-Errico, D.; Vento-Tormo, R.; Sieweke, M.; Ballestar, E. Epigenetic control of myeloid cell differentiation, identity and function. Nat. Rev. Immunol. 2015, 15, 7-17. [CrossRef] [PubMed] 
14. Smale, S.T.; Tarakhovsky, A.; Natoli, G. Chromatin Contributions to the Regulation of Innate Immunity. Annu. Rev. Immunol. 2014, 32, 489-511. [CrossRef]

15. Chen, Y.; Huang, P.; Ai, W.; Li, X.; Guo, W.; Zhang, J.; Yang, J. Histone deacetylase activity is decreased in peripheral blood monocytes in patients with COPD. J. Inflamm. 2012, 9, 10. [CrossRef]

16. Natoli, G.; Ostuni, R. Adaptation and memory in immune responses. Nat. Immunol. 2019, 20, 783-792. [CrossRef]

17. Cosío, B.G.; Mann, B.; Ito, K.; Jazrawi, E.; Barnes, P.J.; Chung, K.F.; Adcock, I.M. Histone acetylase and deacetylase activity in alveolar macrophages and blood mononocytes in asthma. Am. J. Respir. Crit. Care Med. 2004, 170, 141-147. [CrossRef]

18. Shen, J.; Liu, Y.; Ren, X.; Gao, K.; Li, Y.; Li, S.; Yao, J.; Yang, X. Changes in DNA methylation and chromatin structure of pro-inflammatory cytokines stimulated by LPS in broiler peripheral blood mononuclear cells. Poult. Sci. 2016, 95, 1636-1645. [CrossRef]

19. MacDonald, V.E.; Howe, L.J. Histone acetylation: Where to go and how to get there. Epigenetics 2009, 4, 139-143. [CrossRef]

20. Klemm, S.L.; Shipony, Z.; Greenleaf, W.J. Chromatin accessibility and the regulatory epigenome. Nat. Rev. Genet. 2019, 20, 207-220. [CrossRef]

21. Haberland, M.; Montgomery, R.L.; Olson, E.N. The many roles of histone deacetylases in development and physiology: Implications for disease and therapy. Nat. Rev. Genet. 2009, 10, 32-42. [CrossRef] [PubMed]

22. Lee, J.Y.; Kim, N.A.; Sanford, A.; Sullivan, K.E. Histone acetylation and chromatin conformation are regulated separately at the TNF- $\alpha$ promoter in monocytes and macrophages. J. Leukoc. Biol. 2003, 73, 862-871. [CrossRef] [PubMed]

23. Park, G.Y.; Joo, M.; Pedchenko, T.; Blackwell, T.S.; Christman, J.W. Regulation of macrophage cyclooxygenase-2 gene expression by modifications of histone H3. Am. J. Physiol. Cell. Mol. Physiol. 2004, 286, L956-L962. [CrossRef] [PubMed]

24. Chriett, S.; Dabek, A.; Wojtala, M.; Vidal, H.; Balcerczyk, A.; Pirola, L. Prominent action of butyrate over $\beta$-hydroxybutyrate as histone deacetylase inhibitor, transcriptional modulator and anti-inflammatory molecule. Sci. Rep. 2019, 9, 1-14. [CrossRef] [PubMed]

25. Li, M.; van Esch, B.C.A.M.; Henricks, P.A.J.; Folkerts, G.; Garssen, J. The anti-inflammatory effects of short chain fatty acids on lipopolysaccharide- or tumor necrosis factor $\alpha$-stimulated endothelial cells via activation of GPR41/43 and inhibition of HDACs. Front. Pharmacol. 2018, 9, 1-12. [CrossRef]

26. Chang, P.V.; Hao, L.; Offermanns, S.; Medzhitov, R. The microbial metabolite butyrate regulates intestinal macrophage function via histone deacetylase inhibition. Proc. Natl. Acad. Sci. USA 2014, 111, 2247-2252. [CrossRef]

27. Pacis, A.; Tailleux, L.; Morin, A.M.; Lambourne, J.; MacIsaac, J.L.; Yotova, V.; Dumaine, A.; Danckært, A.; Luca, F.; Grenier, J.C.; et al. Bacterial infection remodels the DNA methylation landscape of human dendritic cells. Genome Res. 2015, 25, 1801-1811. [CrossRef]

28. Pacis, A.; Mailhot-Léonard, F.; Tailleux, L.; Randolph, H.E.; Yotova, V.; Dumaine, A.; Grenier, J.C.; Barreiro, L.B. Gene activation precedes DNA demethylation in response to infection in human dendritic cells. Proc. Natl. Acad. Sci. USA 2019, 116, 6938-6943. [CrossRef]

29. Bruniquel, D.; Schwartz, R.H. Selective, stable demethylation of the interleukin-2 gene enhances transcription by an active process. Nat. Immunol. 2003, 4, 235-240. [CrossRef]

30. Wiencke, J.K.; Butler, R.; Hsuang, G.; Eliot, M.; Kim, S.; Sepulveda, M.A.; Siegel, D.; Houseman, E.A.; Kelsey, K.T. The DNA methylation profile of activated human natural killer cells. Epigenetics 2016, 11, 363-380. [CrossRef]

31. Ichiyama, K.; Chen, T.; Wang, X.; Yan, X.; Kim, B.S.; Tanaka, S.; Ndiaye-Lobry, D.; Deng, Y.; Zou, Y.; Zheng, P.; et al. The Methylcytosine Dioxygenase Tet2 Promotes DNA Demethylation and Activation of Cytokine Gene Expression in T Cells. Immunity 2015, 42, 613-626. [CrossRef] [PubMed]

32. Marr, A.K.; MacIsaac, J.L.; Jiang, R.; Airo, A.M.; Kobor, M.S.; McMaster, W.R. Leishmania donovani Infection Causes Distinct Epigenetic DNA Methylation Changes in Host Macrophages. PLoS Pathog. 2014, 10. [CrossRef] [PubMed]

33. Krol, J.; Loedige, I.; Filipowicz, W. The widespread regulation of microRNA biogenesis, function and decay. Nat. Rev. Genet. 2010, 11, 597-610. [CrossRef] [PubMed] 
34. Monticelli, S.; Natoli, G. Short-term memory of danger signals and environmental stimuli in immune cells. Nat. Immunol. 2013, 14, 777-784. [CrossRef] [PubMed]

35. O'Connell, R.M.; Chaudhuri, A.A.; Rao, D.S.; Baltimore, D. Inositol phosphatase SHIP1 is a primary target of miR-155. Proc. Natl. Acad. Sci. USA 2009, 106, 7113-7118. [CrossRef]

36. Mantovani, A.; Netea, M.G. Trained Innate Immunity, Epigenetics, and Covid-19. N. Engl. J. Med. 2020, 383, 1078-1080. [CrossRef] [PubMed]

37. Flanagan, K.L.; Klein, S.L.; Skakkebaek, N.E.; Marriott, I.; Marchant, A.; Selin, L.; Fish, E.N.; Prentice, A.M.; Whittle, H.; Benn, C.S.; et al. Sex differences in the vaccine-specific and non-targeted effects of vaccines. Vaccine 2011, 29, 2349-2354. [CrossRef] [PubMed]

38. Schaltz-Buchholzer, F.; Biering-Sørensen, S.; Lund, N.; Monteiro, I.; Umbasse, P.; Fisker, A.B.; Andersen, A.; Rodrigues, A.; Aaby, P.; Benn, C.S. Early BCG vaccination, hospitalizations, and hospital deaths: Analysis of a secondary outcome in 3 randomized trials from guinea-bissau. J. Infect. Dis. 2019, 219, 624-632. [CrossRef]

39. Leonhardt, J.; Große, S.; Marx, C.; Siwczak, F.; Stengel, S.; Bruns, T.; Bauer, R.; Kiehntopf, M.; Williams, D.L.; Wang, Z.Q.; et al. Candida albicans $\beta$-glucan differentiates human monocytes into a specific subset of macrophages. Front. Immunol. 2018, 9, 1-13. [CrossRef]

40. Arts, R.J.W.; Carvalho, A.; La Rocca, C.; Palma, C.; Rodrigues, F.; Silvestre, R.; Kleinnijenhuis, J.; Lachmandas, E.; Gonçalves, L.G.; Belinha, A.; et al. Immunometabolic pathways in BCG-induced trained immunity. Cell Rep. 2016, 17, 2562-2571. [CrossRef]

41. Novakovic, B.; Habibi, E.; Wang, S.Y.; Arts, R.J.W.; Davar, R.; Megchelenbrink, W.; Kim, B.; Kuznetsova, T.; Kox, M.; Zwaag, J.; et al. $\beta$-Glucan Reverses the Epigenetic State of LPS-Induced Immunological Tolerance. Cell 2016, 167, 1354-1368. [CrossRef] [PubMed]

42. Bekkering, S.; Blok, B.A.; Joosten, L.A.B.; Riksen, N.P.; Van Crevel, R.; Netea, M.G. In Vitro experimental model of trained innate immunity in human primary monocytes. Clin. Vaccine Immunol. 2016, 23, 926-933. [CrossRef] [PubMed]

43. Quintin, J.; Saeed, S.; Martens, J.H.A.; Giamarellos-Bourboulis, E.J.; Ifrim, D.C.; Logie, C.; Jacobs, L.; Jansen, T.; Kullberg, B.J.; Wijmenga, C.; et al. Candida albicans infection affords protection against reinfection via functional reprogramming of monocytes. Cell Host Microbe 2012, 12, 223-232. [CrossRef] [PubMed]

44. Saeed, S.; Quintin, J.; Kerstens, H.H.D.; Rao, N.A.; Aghajanirefah, A.; Matarese, F.; Cheng, S.C.; Ratter, J.; Berentsem, K.; Van Der Ent, M.A.; et al. Epigenetic programming of monocyte-to-macrophage differentiation and trained innate immunity. Science 2014, 345. [CrossRef]

45. Kleinnijenhuis, J.; Quintin, J.; Preijers, F.; Joosten, L.A.B.; Ifrim, D.C.; Saeed, S.; Jacobs, C.; Van Loenhout, J.; De Jong, D.; Hendrik, S.; et al. Bacille Calmette-Guérin induces NOD2-dependent nonspecific protection from reinfection via epigenetic reprogramming of monocytes. Proc. Natl. Acad. Sci. USA 2012, 109, 17537-17542. [CrossRef]

46. Kleinnijenhuis, J.; Quintin, J.; Preijers, F.; Benn, C.S.; Joosten, L.A.B.; Jacobs, C.; Van Loenhout, J.; Xavier, R.J.; Aaby, P.; Van Der Meer, J.W.M.; et al. Long-lasting effects of bcg vaccination on both heterologous th1/th17 responses and innate trained immunity. J. Innate Immun. 2014, 6, 152-158. [CrossRef]

47. Blok, B.A.; Arts, R.J.W.; van Crevel, R.; Benn, C.S.; Netea, M.G. Trained innate immunity as underlying mechanism for the long-term, nonspecific effects of vaccines. J. Leukoc. Biol. 2015, 98, 347-356. [CrossRef]

48. Bekkering, S.; Quintin, J.; Joosten, L.A.B.; Van Der Meer, J.W.M.; Netea, M.G.; Riksen, N.P. Oxidized low-density lipoprotein induces long-term proinflammatory cytokine production and foam cell formation via epigenetic reprogramming of monocytes. Arterioscler. Thromb. Vasc. Biol. 2014, 34, 1731-1738. [CrossRef]

49. Bekkering, S.; Joosten, L.A.B.; Van Der Meer, J.W.M.; Netea, M.G.; Riksen, N.P. Trained innate immunity and atherosclerosis. Curr. Opin. Lipidol. 2013, 24, 487-492. [CrossRef]

50. Dominguez-Andres, J.; Netea, M.G. Long-term reprogramming of the innate immune system. J. Leukoc. Biol. 2019, 105, 329-338. [CrossRef]

51. Shalova, I.N.; Lim, J.Y.; Chittezhath, M.; Zinkernagel, A.S.; Beasley, F.; Hernández-Jiménez, E.; Toledano, V.; Cubillos-Zapata, C.; Rapisarda, A.; Chen, J.; et al. Human monocytes undergo functional re-programming during sepsis mediated by hypoxia-inducible factor-1 $\alpha$. Immunity 2015, 42, 484-498. [CrossRef] [PubMed]

52. Foster, S.L.; Hargreaves, D.C.; Medzhitov, R. Gene-specific control of inflammation by TLR-induced chromatin modifications. Nature 2007, 447, 972-978. [CrossRef] [PubMed] 
53. Tie, F.; Banerjee, R.; Stratton, C.A.; Prasad-Sinha, J.; Stepanik, V.; Zlobin, A.; Diaz, M.O.; Scacheri, P.C.; Harte, P.J. CBP-mediated acetylation of histone H3 lysine 27 antagonizes Drosophila Polycomb silencing. Development 2009, 136, 3131-3141. [CrossRef] [PubMed]

54. Frank, D.N.; St Amand, A.L.; Feldman, R.A.; Boedeker, E.C.; Harpaz, N.; Pace, N.R. Molecular-phylogenetic characterization of microbial community imbalances in human inflammatory bowel diseases. Proc. Natl. Acad. Sci. USA 2007, 104, 13780-13785. [CrossRef] [PubMed]

55. Silva, L.G.; Ferguson, B.S.; Avila, A.S.; Faciola, A.P. Sodium propionate and sodium butyrate effects on histone deacetylase (HDAC) activity, histone acetylation, and inflammatory gene expression in bovine mammary epithelial cells. J. Anim. Sci. 2018, 96, 5244-5252. [CrossRef] [PubMed]

56. Venegas, D.P.; De La Fuente, M.K.; Landskron, G.; González, M.J.; Quera, R.; Dijkstra, G.; Harmsen, H.J.M.; Faber, K.N.; Hermoso, M.A. Short chain fatty acids (SCFAs)mediated gut epithelial and immune regulation and its relevance for inflammatory bowel diseases. Front. Immunol. 2019, 10. [CrossRef]

57. Kelly, C.J.; Zheng, L.; Campbell, E.L.; Saeedi, B.; Scholz, C.C.; Bayless, A.J.; Wilson, K.E.; Glover, L.E.; Kominsky, D.J.; Magnuson, A.; et al. Crosstalk between Microbiota-Derived Short-Chain Fatty Acids and Intestinal Epithelial HIF Augments Tissue Barrier Function. Cell Host Microbe 2015, 17, 662-671. [CrossRef]

58. Hesham, H.M.; Lasheen, D.S.; Abouzid, K.A.M. Chimeric HDAC inhibitors: Comprehensive review on the HDAC-based strategies developed to combat cancer. Med. Res. Rev. 2018, 38, 2058-2109. [CrossRef]

59. Eckschlager, T.; Plch, J.; Stiborova, M.; Hrabeta, J. Histone deacetylase inhibitors as anticancer drugs. Int. J. Mol. Sci. 2017, 18, 1414. [CrossRef]

60. McClure, J.J.; Li, X.; Chou, C.J. Advances and Challenges of HDAC Inhibitors in Cancer Therapeutics, 1st ed.; Elsevier: Amsterdam, The Netherlands, 2018.

61. Gao, X.; Shen, L.; Li, X.; Liu, J. Efficacy and toxicity of histone deacetylase inhibitors in relapsed/refractory multiple myeloma: Systematic review and meta-analysis of clinical trials. Exp. Ther. Med. 2019, 18, 1057-1068. [CrossRef]

62. Cengiz Seval, G.; Beksac, M. A comparative safety review of histone deacetylase inhibitors for the treatment of myeloma. Expert Opinion Drug Saf. 2019, 18, 563-571. [CrossRef] [PubMed]

63. Kobayashi, M.; Mikami, D.; Kimura, H.; Kamiyama, K.; Morikawa, Y.; Yokoi, S.; Kasuno, K.; Takahashi, N.; Taniguchi, T.; Iwano, M. Short-chain fatty acids, GPR41 and GPR43 ligands, inhibit TNF- $\alpha$-induced MCP-1 expression by modulating p38 and JNK signaling pathways in human renal cortical epithelial cells. Biochem. Biophys. Res. Commun. 2017, 486, 499-505. [CrossRef] [PubMed]

64. Ang, Z.; Xiong, D.; Wu, M.; Ding, J.L. FFAR2-FFAR3 receptor heteromerization modulates short-chain fatty acid sensing. FASEB J. 2018, 32, 289-303. [CrossRef] [PubMed]

65. Hustoft, T.N.; Hausken, T.; Ystad, S.O.; Valeur, J.; Brokstad, K.; Hatlebakk, J.G.; Lied, G.A. Effects of varying dietary content of fermentable short-chain carbohydrates on symptoms, fecal microenvironment, and cytokine profiles in patients with irritable bowel syndrome. Neurogastroenterol. Motil. 2017, 29. [CrossRef] [PubMed]

66. Demehri, F.R.; Frykman, P.K.; Cheng, Z.; Ruan, C.; Wester, T.; Nordenskjöld, A.; Kawaguchi, A.; Hui, T.T.; Granström, A.L.; Funari, V.; et al. Altered fecal short chain fatty acid composition in children with a history of Hirschsprung-associated enterocolitis. J. Pediatr. Surg. 2016, 51, 81-86. [CrossRef]

67. Mazzawi, T.; Hausken, T.; Hov, J.R.; Valeur, J.; Sangnes, D.A.; El-Salhy, M.; Gilja, O.H.; Hatlebakk, J.G.; Lied, G.A. Clinical response to fecal microbiota transplantation in patients with diarrhea-predominant irritable bowel syndrome is associated with normalization of fecal microbiota composition and short-chain fatty acid levels. Scand. J. Gastroenterol. 2019, 54, 690-699. [CrossRef]

68. van der Beek, C.M.; Canfora, E.E.; Kip, A.M.; Gorissen, S.H.M.; Olde Damink, S.W.M.; van Eijk, H.M.; Holst, J.J.; Blaak, E.E.; Dejong, C.H.C.; Lenaerts, K. The prebiotic inulin improves substrate metabolism and promotes short-chain fatty acid production in overweight to obese men. Metabolism 2018, 87, 25-35. [CrossRef]

69. Canfora, E.E.; van der Beek, C.M.; Jocken, J.W.E.; Goossens, G.H.; Holst, J.J.; Olde Damink, S.W.M.; Lenaerts, K.; Dejong, C.H.C.; Blaak, E.E. Colonic infusions of short-chain fatty acid mixtures promote energy metabolism in overweight/obese men: A randomized crossover trial. Sci. Rep. 2017, 7, 2360. [CrossRef]

70. Zhao, L.; Zhang, F.; Ding, X.; Wu, G.; Lam, Y.Y.; Wang, X.; Fu, H.; Xue, X.; Lu, C.; Ma, J.; et al. Gut bacteria selectively promoted by dietary fibers alleviate type 2 diabetes. Science 2018, 359, 1151-1156. [CrossRef] 
71. Hague, A.; Elder, D.J.; Hicks, D.J.; Paraskeva, C. Apoptosis in colorectal tumour cells: Induction by the short chain fatty acids butyrate, propionate and acetate and by the bile salt deoxycholate. Int. J. Cancer 1995, 60, 400-406. [CrossRef]

72. Underwood, M.A.; Salzman, N.H.; Bennett, S.H.; Barman, M.; Mills, D.A.; Marcobal, A.; Tancredi, D.J.; Bevins, C.L.; Sherman, M.P. A randomized placebo-controlled comparison of 2 prebiotic/probiotic combinations in preterm infants: Impact on weight gain, intestinal microbiota, and fecal short-chain fatty acids. J. Pediatr. Gastroenterol. Nutr. 2009, 48, 216-225. [CrossRef] [PubMed]

73. Erny, D.; Hrabě de Angelis, A.L.; Jaitin, D.; Wieghofer, P.; Staszewski, O.; David, E.; Keren-Shaul, H.; Mahlakoiv, T.; Jakobshagen, K.; Buch, T.; et al. Host microbiota constantly control maturation and function of microglia in the CNS. Nat. Neurosci. 2015, 18, 965-977. [CrossRef] [PubMed]

74. Burokas, A.; Arboleya, S.; Moloney, R.D.; Peterson, V.L.; Murphy, K.; Clarke, G.; Stanton, C.; Dinan, T.G.; Cryan, J.F. Targeting the Microbiota-Gut-Brain Axis: Prebiotics Have Anxiolytic and Anfiguretidepressant-like Effects and Reverse the Impact of Chronic Stress in Mice. Biol. Psychiatry 2017, 82, 472-487. [CrossRef] [PubMed]

75. Donohoe, D.R.; Collins, L.B.; Wali, A.; Bigler, R.; Sun, W.; Bultman, S.J. The Warburg effect dictates the mechanism of butyrate-mediated histone acetylation and cell proliferation. Mol. Cell 2012, 48, 612-626. [CrossRef]

76. Raqib, R.; Sarker, P.; Mily, A.; Alam, N.H.; Arifuzzaman, A.S.M.; Rekha, R.S.; Andersson, J.; Gudmundsson, G.H.; Cravioto, A.; Agerberth, B. Efficacy of sodium butyrate adjunct therapy in shigellosis: A randomized, double-blind, placebo-controlled clinical trial. BMC Infect. Dis. 2012, 12, 111. [CrossRef]

77. Kim, M.H.; Kang, S.G.; Park, J.H.; Yanagisawa, M.; Kim, C.H. Short-chain fatty acids activate GPR41 and GPR43 on intestinal epithelial cells to promote inflammatory responses in mice. Gastroenterology 2013, 145, 396-406. [CrossRef]

78. Macia, L.; Tan, J.; Vieira, A.T.; Leach, K.; Stanley, D.; Luong, S.; Maruya, M.; Ian McKenzie, C.; Hijikata, A.; Wong, C.; et al. Metabolite-sensing receptors GPR43 and GPR109A facilitate dietary fibre-induced gut homeostasis through regulation of the inflammasome. Nat. Commun. 2015, 6. [CrossRef]

79. Asarat, M.; Vasiljevic, T.; Apostolopoulos, V.; Donkor, O. Short-Chain Fatty Acids Regulate Secretion of IL-8 from Human Intestinal Epithelial Cell Lines in vitro. Immunol. Investig. 2015, 44, 678-693. [CrossRef]

80. Bailón, E.; Cueto-Sola, M.; Utrilla, P.; Rodríguez-Cabezas, M.E.; Garrido-Mesa, N.; Zarzuelo, A.; Xaus, J.; Gálvez, J.; Comalada, M. Butyrate in vitro immune-modulatory effects might be mediated through a proliferation-related induction of apoptosis. Immunobiology 2010, 215, 863-873. [CrossRef]

81. Liu, L.; Li, L.; Min, J.; Wang, J.; Wu, H.; Zeng, Y.; Chen, S.; Chu, Z. Butyrate interferes with the differentiation and function of human monocyte-derived dendritic cells. Cell. Immunol. 2012, 277, 66-73. [CrossRef]

82. Vinolo, M.A.R.; Rodrigues, H.G.; Festuccia, W.T.; Crisma, A.R.; Alves, V.S.; Martins, A.R.; Amaral, C.L.; Fiamoncini, J.; Hirabara, S.M.; Sato, F.T.; et al. Tributyrin attenuates obesity-associated inflammation and insulin resistance in high-fat-fed mice. Am. J. Physiol. Metab. 2012, 303, E272-E282. [CrossRef] [PubMed]

83. Cox, M.A.; Jackson, J.; Stanton, M.; Rojas-Triana, A.; Bober, L.; Laverty, M.; Yang, X.; Zhu, F.; Liu, J.; Wang, S.; et al. Short-chain fatty acids act as antiinflammatory mediators by regulating prostaglandin $\mathrm{E}(2)$ and cytokines. World J. Gastroenterol. 2009, 15, 5549-5557. [CrossRef] [PubMed]

84. Zeng, X.; Sunkara, L.T.; Jiang, W.; Bible, M.; Carter, S.; Ma, X.; Qiao, S.; Zhang, G. Induction of porcine host defense peptide gene expression by short-chain fatty acids and their analogs. PLoS ONE 2013, 8, e72922. [CrossRef] [PubMed]

85. Millard, A.L.; Mertes, P.M.; Ittelet, D.; Villard, F.; Jeannesson, P.; Bernard, J. Butyrate affects differentiation, maturation and function of human monocyte-derived dendritic cells and macrophages. Clin. Exp. Immunol. 2002, 130, 245-255. [CrossRef]

86. Singh, N.; Thangaraju, M.; Prasad, P.D.; Martin, P.M.; Lambert, N.A.; Boettger, T.; Offermanns, S.; Ganapathy, V. Blockade of dendritic cell development by bacterial fermentation products butyrate and propionate through a transporter (Slc5a8)-dependent inhibition of histone deacetylases. J. Biol. Chem. 2010, 285, 27601-27608. [CrossRef]

87. Sepahi, A.; Liu, Q.; Friesen, L.; Kim, C.H. Dietary fiber metabolites regulate innate lymphoid cell responses. Mucosal Immunol. 2020. [CrossRef] 
88. Lewis, G.; Wang, B.; Shafiei Jahani, P.; Hurrell, B.P.; Banie, H.; Aleman Muench, G.R.; Maazi, H.; Helou, D.G.; Howard, E.; Galle-Treger, L.; et al. Dietary Fiber-Induced Microbial Short Chain Fatty Acids Suppress ILC2-Dependent Airway Inflammation. Front. Immunol. 2019, 10, 2051. [CrossRef]

89. Theiler, A.; Bärnthaler, T.; Platzer, W.; Richtig, G.; Peinhaupt, M.; Rittchen, S.; Kargl, J.; Ulven, T.; Marsh, L.M.; Marsche, G.; et al. Butyrate ameliorates allergic airway inflammation by limiting eosinophil trafficking and survival. J. Allergy Clin. Immunol. 2019, 144, 764-776. [CrossRef]

90. Louis, P.; Flint, H.J. Formation of propionate and butyrate by the human colonic microbiota. Environ. Microbiol. 2017, 19, 29-41. [CrossRef]

91. Adamek, K.; Skonieczna-Żydecka, K.; Wegrzyn, D.; Łoniewska, B. Prenatal and early childhood development of gut microbiota. Eur. Rev. Med. Pharmacol. Sci. 2019, 23, 9667-9680. [CrossRef]

92. Perez-Muñoz, M.E.; Arrieta, M.-C.; Ramer-Tait, A.E.; Walter, J. A critical assessment of the "sterile womb" and "in utero colonization" hypotheses: Implications for research on the pioneer infant microbiome. Microbiome 2017, 5, 48. [CrossRef] [PubMed]

93. Rutayisire, E.; Huang, K.; Liu, Y.; Tao, F. The mode of delivery affects the diversity and colonization pattern of the gut microbiota during the first year of infants' life: A systematic review. BMC Gastroenterol. 2016, 16, 86. [CrossRef] [PubMed]

94. Maher, S.E.; O’Brien, E.C.; Moore, R.L.; Byrne, D.F.; Geraghty, A.A.; Saldova, R.; Murphy, E.F.; Van Sinderen, D.; Cotter, P.D.; McAuliffe, F.M. The association between the maternal diet and the maternal and infant gut microbiome: A systematic review. Br. J. Nutr. 2020, 1-29. [CrossRef] [PubMed]

95. Fjalstad, J.W.; Esaiassen, E.; Juvet, L.K.; van den Anker, J.N.; Klingenberg, C. Antibiotic therapy in neonates and impact on gut microbiota and antibiotic resistance development: A systematic review. J. Antimicrob. Chemother. 2018, 73, 569-580. [CrossRef]

96. Matsuki, T.; Yahagi, K.; Mori, H.; Matsumoto, H.; Hara, T.; Tajima, S.; Ogawa, E.; Kodama, H.; Yamamoto, K.; Yamada, T.; et al. A key genetic factor for fucosyllactose utilization affects infant gut microbiota development. Nat. Commun. 2016, 7, 11939. [CrossRef]

97. Louis, P.; Flint, H.J. Diversity, metabolism and microbial ecology of butyrate-producing bacteria from the human large intestine. FEMS Microbiol. Lett. 2009, 294, 1-8. [CrossRef]

98. Pham, V.T.; Lacroix, C.; Braegger, C.P.; Chassard, C. Early colonization of functional groups of microbes in the infant gut. Environ. Microbiol. 2016, 18, 2246-2258. [CrossRef]

99. Appert, O.; Garcia, A.R.; Frei, R.; Roduit, C.; Constancias, F.; Neuzil-Bunesova, V.; Ferstl, R.; Zhang, J.; Akdis, C.; Lauener, R.; et al. Initial butyrate producers during infant gut microbiota development are endospore formers. Environ. Microbiol. 2020. [CrossRef]

100. Francino, M.P. Early development of the gut microbiota and immune health. Pathog. 2014, 3, 769-790. [CrossRef]

101. Atarashi, K.; Tanoue, T.; Ando, M.; Kamada, N.; Nagano, Y.; Narushima, S.; Suda, W.; Imaoka, A.; Setoyama, H.; Nagamori, T.; et al. Th17 Cell Induction by adhesion of microbes to intestinal epithelial cells. Cell 2015, 163, 367-380. [CrossRef]

102. Macpherson, A.J.; Uhr, T. Induction of protective IgA by intestinal dendritic cells carrying commensal bacteria. Science 2004, 303, 1662-1665. [CrossRef] [PubMed]

103. de Jong, S.E.; Olin, A.; Pulendran, B. The Impact of the microbiome on immunity to vaccination in humans. Cell Host Microbe 2020, 28, 169-179. [CrossRef]

104. Round, J.L.; Mazmanian, S.K. The gut microbiota shapes intestinal immune responses during health and disease. Nat. Rev. Immunol. 2009, 9, 313-323. [CrossRef] [PubMed]

105. Uchiyama, R.; Chassaing, B.; Zhang, B.; Gewirtz, A.T. Antibiotic treatment suppresses rotavirus infection and enhances specific humoral immunity. J. Infect. Dis. 2014, 210, 171-182. [CrossRef] [PubMed]

106. Oh, J.Z.; Ravindran, R.; Chassaing, B.; Carvalho, F.A.; Maddur, M.S.; Bower, M.; Hakimpour, P.; Gill, K.P.; Nakaya, H.I.; Yarovinsky, F.; et al. TLR5-mediated sensing of gut microbiota is necessary for antibody responses to seasonal influenza vaccination. Immunity 2014, 41, 478-492. [CrossRef]

107. Lynn, M.A.; Tumes, D.J.; Choo, J.M.; Sribnaia, A.; Blake, S.J.; Leong, L.E.X.; Young, G.P.; Marshall, H.S.; Wesselingh, S.L.; Rogers, G.B.; et al. Early-Life Antibiotic-Driven Dysbiosis Leads to Dysregulated Vaccine Immune Responses in Mice. Cell Host Microbe 2018, 23, 653-660. [CrossRef] [PubMed] 
108. Harris, V.C.; Armah, G.; Fuentes, S.; Korpela, K.E.; Parashar, U.; Victor, J.C.; Tate, J.; de Weerth, C.; Giaquinto, C.; Wiersinga, W.J.; et al. Significant Correlation Between the Infant Gut Microbiome and Rotavirus Vaccine Response in Rural Ghana. J. Infect. Dis. 2017, 215, 34-41. [CrossRef]

109. Harris, V.; Ali, A.; Fuentes, S.; Korpela, K.; Kazi, M.; Tate, J.; Parashar, U.; Wiersinga, W.J.; Giaquinto, C.; de Weerth, C.; et al. Rotavirus vaccine response correlates with the infant gut microbiota composition in Pakistan. Gut Microbes 2018, 9, 93-101. [CrossRef]

110. Huda, M.N.; Lewis, Z.; Kalanetra, K.M.; Rashid, M.; Ahmad, S.M.; Raqib, R.; Qadri, F.; Underwood, M.A.; Mills, D.A.; Stephensen, C.B. Stool microbiota and vaccine responses of infants. Pediatrics 2014, 134, e362-e372. [CrossRef]

111. Grassly, N.C.; Praharaj, I.; Babji, S.; Kaliappan, S.P.; Giri, S.; Venugopal, S.; Parker, E.P.K.; Abraham, A.; Muliyil, J.; Doss, S.; et al. The effect of azithromycin on the immunogenicity of oral poliovirus vaccine: A double-blind randomised placebo-controlled trial in seronegative Indian infants. Lancet Infect. Dis. 2016, 16, 905-914. [CrossRef]

112. Hagan, T.; Cortese, M.; Rouphael, N.; Boudreau, C.; Linde, C.; Maddur, M.S.; Das, J.; Wang, H.; Guthmiller, J.; Zheng, N.-Y.; et al. Antibiotics-Driven Gut Microbiome Perturbation Alters Immunity to Vaccines in Humans. Cell 2019, 178, 1313-1328. [CrossRef] [PubMed]

113. Cleophas, M.C.P.; Ratter, J.M.; Bekkering, S.; Quintin, J.; Schraa, K.; Stroes, E.S.; Netea, M.G.; Joosten, L.A.B. Effects of oral butyrate supplementation on inflammatory potential of circulating peripheral blood mononuclear cells in healthy and obese males. Sci. Rep. 2019, 9, 775. [CrossRef] [PubMed]

(C) 2020 by the authors. Licensee MDPI, Basel, Switzerland. This article is an open access article distributed under the terms and conditions of the Creative Commons Attribution (CC BY) license (http://creativecommons.org/licenses/by/4.0/). 